\title{
ETNICIDAD SUDAMERICANA SEGÚN LA ÉPOCA DEL CRISTAL CON QUE SE MIRE Y MIDA
}

\author{
SOUTH-AMERICAN ETHNICITY CONSIDERING HOW YOU LOOK AND MEASURE THE PERIOD INVOLVED
}

Jorge Kulemeyer *

jorgeak@gmail.com

\begin{abstract}
RESUMEN: En el transcurso de los últimos 35 años en los países sudamericanos se han producido modificaciones constitucionales, adhesiones a convenios internacionales, y creaciones de leyes específicas referidas a los grupos indígenas lo que ha intensificado los requerimientos de cifras oficiales que den cuenta del volumen y caracterización de los pueblos indígenas en los países latinoamericanos (GOLDBERG, 2007). Este escrito propone una aproximación a la valoración de los resultados de los censos de población aborigen, producidos a distintas escalas en algunos de estos países, que han dado lugar a lecturas y debates sociales y políticos y, muchas veces, han servido de sustento argumental para el impulso de lineamientos gubernamentales. En principio puede parecer sorprendente el hecho que los resultados resulten casi siempre contradictorios en relación a otras mediciones realizadas en el mismo territorio con el mismo propósito, incluso cuando son muy cercanas en el tiempo. Se propone, al menos como parte de la explicación, que, por un lado, que cada uno de los resultados obtenidos no necesariamente es inexacto sino que resulta un reflejo de las circunstancias políticas coyunturales que hacen al conjunto de la población al momento de la realización de la consulta y de los intereses de quienes la organizan. Por otra parte se plantea la dificultad de pretender cuantificar con valores absolutos aquello que, en la mayoría de los casos, se plantea en términos subjetivos.
\end{abstract}

PalABRAS Clave: Etnicidad, Sudamérica, Censos.

ABSTRACT: : During the last 35 years constitutional changes, support to international agreements and the creation of specific laws regarding indigenous groups have been produced in South American countries. Consequently, there is a demand for having official figures related to volume and characterization of the indigenous people in Latin-American countries (GOLDBERG, 2007). This paper recommends an approach to evaluate the results of the aborigine population census, produced at different scales in some of these countries, and which have resulted in readings and social and political debates, and many times, have been the source for governmental guidelines. At the beginning it can be considered as surprising the fact that the results are sometimes contradictory as related to other measurements which were made in the same territory and with the same purpose, even when they are very close in time. It is proposed, as part of the explanation, that on one hand each of the gathered results is not necessarily incorrect but it shows the current political situation related to the population at the moment of the study and also of the interests of those who organize it; on the other hand it considers the difficulty of trying to quantify with absolute figures that, which in most cases, is considered in subjective terms.

KEYWORDS: Ethnicity, South-America, Census.

\section{Los procesos regionales de racialización y etnificación}

Una de las tendencias sociopolíticas dominantes en la actualidad latinoamericana de las últimas décadas consiste en la profundización de las políticas oficiales tendientes al

\footnotetext{
* Facultad de Humanidades y Ciencias Sociales, Universidad Nacional de Jujuy (Argentina).
} 
desarrollo de políticas organizadas en torno a la posibilidad de autoadscripción étnica de los integrantes de la sociedad. (BRAVO-MORENO, 2015) refiere de la existencia de un acuerdo amplio reflejado en la literatura en el sentido de que "... la racialización es un proceso pernicioso al que se subyuga a otros individuos como parte de una red de relaciones de poder". De ello deviene el asignar un significado al propio grupo como "raza" o grupo étnico e infundir este significado con atributos identitarios positivos o singulares hacia sí mismo y negativos en la consideración de otros. Ya en el período colonial en América los grupos sociales fueron organizados, muchas veces en torno a la idea "raza". El color de piel se volvió fundamental para construir jerarquías sociales con relaciones de poder desiguales. En la mayoría de los casos se observó una clasificación jerárquica de razas donde la dominación social y laboral fue de la población blanca de origen europeo en tanto que indígenas y negros sufrieron situaciones de dominación y sometimiento. Con la conquista española

... la categoría "indio" no designaba especificidad cultural, biológica o lingüística alguna, sino que fue instituida para designar al conjunto diverso y heterogéneo de poblaciones precolombinas: Fue una categoría política y administrativa destinada a marcar a los vencidos, a los colonizados, a los dominados, sin importar cuan diferentes hayan sido entre sí. (YUDI, 2015, p. 20).

A partir de las ideas inspiradas en el liberalismo y el romanticismo europeo de muchos pensadores que constituyeron la dirigencia de los movimientos emancipadores latinoamericanos que dieron lugar al surgimiento de los Estado/Nación (por ejemplo, la Asamblea del año XIII en el Río de la Plata) dando lugar a la difusión de la concepción de que todos los ciudadanos eran iguales ante la ley, con igualdad de oportunidades en un marco de equidad independientemente de su origen racial o geográfico. La idea que Argentina constituía un "crisol de razas", que habría sido consolidada en el ámbito de las ciencias sociales por el sociólogo italiano Gino Germani (MARQUIEGUI, 1999) puede ayudar explicar, al menos en parte, la ausencia de censos nacionales de datos sobre etnicidad, una distinción que, al menos en el discurso oficial, era considerada anacrónica y negativa para el tejido social.

En el primer Censo Nacional de la Argentina, realizado en 1869, por primera vez no son tenidas en cuenta las categorías étnicas. La consulta incluyó la averiguación sobre profesión, oficio, ocupación o medio de vida; instrucción: saber leer y escribir; condiciones especiales con las siguientes alternativas: ilegítimos, mancebos, dementes, sordo-mudos, 
ciegos, cretinos imbéciles, estúpidos opas, con bocio o coto; inválidos: por acción de guerra o por accidente de trabajo, huérfanos (GROSSO, 2008, p. 57).

Las posturas marxistas, y no solo ellas, consideran que el aspecto estructurante de una sociedad está dado marcado por la existencia de clases sociales. "En oposición a esta concepción de las formas de organización social del capitalismo, en tiempos recientes la etnicidad se percibe frecuentemente sobre todo a partir de una clasificación de acuerdo a diferencias culturales, que pasa a ser vista como la causa de la desigualdad" (BASTOS, 1996, p. 174). En América latina el concepto de campesinado, una categoría afín a la izquierda tradicional, ha sido aceptado en la mayoría de los países pero en las últimas décadas algunos teóricos la consideran inapropiadas. El caso boliviano ofrece una referencia histórica concreta a través de las controversias en torno al modelo impulsado por la Revolución Nacional de 1952, liderada por el Movimiento Nacionalista Revolucionario (MNR), que tenía el propósito de construir un solo modelo de mestizaje tendiente a lo monocultural desarrollado en base al sentido de pertenencia a la nación boliviana. Según Albó (2009), fue a partir de las reformas introducidas por la revolución que el conjunto de los bolivianos fueron adquiriendo la conciencia y el gusto de que Bolivia era también una Nación-Estado. Bajo el legítimo argumento de eliminar la discriminación racial contra los "indios", se los empezó a llamar sólo "campesinos" y sus organizaciones comunales se transformaron en "sindicatos campesinos", aunque ya no tuvieran patrón ni reivindicaciones claras como la recuperación de sus tierras. El ideal del Estado del '52 era la construcción de una sociedad más inclusiva, ciertamente, pero uniformada por una cultura "mestiza", en el sentido de que ya no sería "indígena" sino una cultura común cada vez más cercana a la de la sociedad blanca-criolla dominante, dentro de una mentalidad "civilizatoria". Esto se hizo desconociendo y hasta pretendiendo borrar las identidades culturales de todos estos pueblos (ALBÓ, 2009, p. 67). Simultáneamente, el fuerte impulso dado por la Revolución del '52 a la cultura Tiwanaku, a la idea de centralidad como referente de la identidad y a la conciencia nacional boliviana ha sido interpretado como un denodado intento por dar lugar a una idea de nación mestizo-criolla "expropiando de esa manera a los pueblos andinos de su memoria histórica" (RIVERA CUSICANQUI, 1980).

A partir de los ochenta del siglo pasado las actuales políticas públicas en Latinoamérica, impulsadas a partir del despunte neoliberal, sostienen la premisa de la 
necesidad de implementar una política de "discriminación positiva" en favor de los grupos indígenas a los que se identifica generalmente como una minoría con condiciones de vida y localización marginal respecto a la sociedad dominante y que se encuentra necesitada de un tratamiento tutelar. En la base de este razonamiento se encuentra el supuesto de que los pueblos indígenas (al igual que los grupos afrodescendientes) han recuperado, especialmente a partir de los noventa del siglo pasado, una notoriedad como realidades culturales, políticas e históricas que en nada serían comparables ni asimilables a otros grupos vulnerables (JASPERS-FAIJER, 2006). En la práctica se han generado posicionamientos que dejan en peores condiciones relativas a aquellos (criollos, campesinos, etc.) que comparten el mismo territorio y son igualmente estructuralmente pobres pero que, por alguna razón no deciden optar por la autoadscripción formal a un grupo étnico con raíces prehispánicas (KULEMEYER, 2015). Esta lógica de distribución de los recursos estatales está asociada a la necesidad de contar con una versión sobre el pasado acorde con demandas que, este sentido, son casi generalizadas en muy diversos ámbitos pero que debe ser refrendada en el presente con evidencias fácticas que sean producto y reflejo de la pertenencia étnica que se plantea como propia y que, con frecuencia, termina siendo de carácter esencialista.

En los 80, la condición para la obtención de préstamos por parte de los Estados dependía de la privatización de las actividades públicas asociadas al manejo de recursos en general y de los servicios esenciales en particular. A partir de los 90 los organismos multilaterales y los gobiernos centrales renuevan su interés por las instituciones públicas (BANCO MUNDIAL, 2007) que son reorientadas en cuanto a sus objetivos acompañado de un nuevo y generalizado proceso de recomposición del accionar de los Estados bajo formas distantes dadas por nuevas formas de mediación con la población "que algunos politólogos han llamado el Estado a la distancia o el Estado gestionario, managerial" (ROUVIÈRE, 2014).

Para la adopción de estas políticas se toma referencias del modelo estadounidense donde la definición legal de indio incluye una serie de categorizaciones según los grados de pertenencia a un determinado grupo tribal de los individuos basados en consideraciones sobre el porcentaje de sangre indígena de los individuos. Raza es más un constructo político acordado socialmente que un criterio biológico de definición. La pertenencia a un grupo 
étnico tiene la intención de fijar una referencia mediante el cual se establece la relación con los otros y se otorgan derechos políticos y ciudadanía (GUANUMEN, 2013).

En las últimas décadas se observan dos procesos concurrentes y, en apariencia, contradictorios entre sí. Por un lado se presentan procesos que algunos definen como tendientes a la unificación base de un Estado plurinacional, ha llevado, en la práctica, " $a$ un tránsito a la monoculturalidad, pues tras de las loas a todos los pueblos originarios, en realidad lo que se sobrevalora y se pone como el centro del discurso estatal, es todo aquello que proviene de la cultura aymara" (TORANZO ROCA, 2009, p. 54-55). En esta misma línea, para el caso de Guatemala se hace referencia a una mayanización (González Ponciano, 2008).

Puede que resulte una simplificación extrema sostener que la escasa presencia que ha tenido durante décadas de la categoría indígena en los censos nacionales no se deba exclusivamente a posturas discriminatorias o el interés de sostener una invisibilización de parte de la realidad poblacional o la búsqueda de negar el pasado. Simultáneamente se observa que “... la reflexión académica sobre la movilización política de los indios en Latinoamérica está adquiriendo cada vez más importancia en los últimos años, a la zaga de la presencia que están consiguiendo como interlocutores para los poderes públicos y organismos establecidos" (BASTOS, 1996, p. 161).

En el imaginario dominante en el presente, muchas veces impulsado desde las esferas gubernamentales y otros grupos de poder, la población indígena se caracterizaría por:

* estar radicada en áreas rurales marginales; ${ }^{1}$

* ser la referencia presente de lo "nuestro" (jujeño, argentino, americano) pasado prehispánico; de "nuestro" territorio (en especial quebrada y/o puna en el caso de Jujuy);

* representar el espíritu y testimonio vivo de los habitantes originales del continente americano, conquistado por europeos pero nunca doblegados en sus coherentes y auténticos principios;

\footnotetext{
${ }^{1}$ Así, por ejemplo, las declaraciones a la prensa del actual gobernador de la provincia de Jujuy (noroeste argentino), Gerardo Morales, quien señaló en referencia a una reunión mantenida por el Papa Francisco I y una dirigente social que se autodefine como indígena que: "Yo creo que el Papa fue engañado. Porque hay muchos que se ponen de una pluma y se creen que son representantes de pueblos originarios. Milagro Sala no es originaria, es tan urbana como usted y yo". Fuente: La Nación, 16 de mayo de 2016 http://www.lanacion.com.ar/1899360-gerardo-morales-milagro-sala-no-es-originaria-es-una-gran-delincuente.
} 
* a pesar de haber sufrido una colonización cultural atroz, preservan ciertas tradiciones de sus antepasados que hacen a la continuidad esencial de su forma de pensar y vivir desde tiempos prehispánicos. En el discurso aparece como central el uso del concepto "ancestral", indefinido en su profundidad temporal y, en general, sin mayor caracterización específica;

* una economía de subsistencia que estaría, al menos parcialmente, basada en la producción de artesanías cuya factura y diseño mantendría continuidad y similitud con las manufacturas de sus antepasados habiendo, además, todos ellos pertenecido a un mismo grupo étnico a lo largo del tiempo;

* uso de estrategias de comercialización de su reducida producción en base a circuitos y modalidades precapitalistas;

* vivir en la pobreza (condiciones de vida por debajo de los promedios nacionales);

* padecer situaciones de racismo y exclusión;

* no adecuarse a los ritmos de trabajo/producción requeridos para la integración social lo que da a lugar a que solo puedan acceder a trabajos de baja calificación;

* necesitar ayuda (tutela) por parte de la sociedad mayor (Estado en sus distintas versiones, ONG's nacionales y extranjeras, etc).

\section{Los censos y la población aborigen}

Rodríguez Wong y Sánchez (2014) señalan que la literatura demográfica sobre pueblos indígenas y afrodescendientes es relativamente escasa. Al igual que en el caso de los indígenas “... la cuantificación oficial de los afrodescendientes viene siendo una exigencia de actores globales sobre los Estados nacionales en América Latina..." (LÓPEZ, 2006, p. 266) como parte de una serie de medidas propias del actual nuevo orden político y económico que, en gran medida, son impuestas y aceptadas por todos los países de la región. Como en toda imposición, las reglas de juego pueden sostenerse gracias a que existen sectores que se ven beneficiados en detrimento de otros. Esta "concientización" sobre la necesidad de documentar la dinámica demográfica de estos segmentos poblacionales enfrenta, muestra limitantes de diversa índole, algunas de las cuales son:

1. la dificultad de las definiciones que se envuelven en este universo;

2. el desconocimiento del tamaño de la población indígena y afrodescendiente;

3. la calidad de los datos disponibles (como consecuencia de lo anterior);

4. la dificultad para discernir objetividad de prejuicio e ideología.

En el caso de los pueblos indígenas, las agencias internacionales estiman que, actualmente, estos alcanzarían entre 250 a 350 millones alrededor del mundo, representando el $5 \%$ de la población mundial. En total podrían ser 370 millones viviendo en 
más de 70 países en todo el mundo. Los esfuerzos internacionales por dimensionar la población indígena llevan ya algunas décadas y su falta de precisión está relacionada a la naturaleza de la definición de pueblo indígena y al reconocimiento del derecho de una persona a ser identificada a sí misma y ser reconocida y aceptada en su comunidad como indígena (RODRÍGUEZ WONG y SÁNCHEZ, 2014).

Sobre la base de los datos de los últimos censos disponibles en la región, en 2010 había alrededor de 42 millones de indígenas en América Latina, que representaban cerca del $8 \%$ de la población total. México, Guatemala, Perú y Bolivia tenían las poblaciones más extensas, tanto en términos absolutos como proporcionales, representando más del $80 \%$ (34 millones) del total regional (BANCO MUNDIAL, 2015).

Bonfil Batalla (1972) observa que, en general,

... cualquier intento por definir a la población indígena de acuerdo con un solo criterio, se considera insuficiente. El uso exclusivo de indicadores biológicos, conectado estrechamente con la concepción del indio en términos raciales, resulta obsoleto dada la amplitud de la miscigenación ocurrida entre poblaciones muy diversas -entre sí y dentro de cada una de ellas-, lo que hace que en América todos resultemos mestizos.

\section{Las contradicciones de los datos demográficos de los censos recientes de indígenas en países de Sudamérica}

Las aparentes fuertes contradicciones que en corto lapso se registran en los censos de poblaciones de indígenas en países de Sudamérica son, entre otras razones, consecuencia de los vaivenes de las políticas de mayor o menor grado de especificidad y los intereses que, en cada caso, resultan de ella. Es decir, las contradicciones que arroja la comparación de las cifras resultantes de censos, generalmente separada la realización del uno y el otro por solo una década, pueden ser mejor interpretadas si se tienen en cuenta las políticas nacionales e internacionales en la materia.

En Bolivia el censo del año 1900 determinó la población indígena alcanzaba el 48,5\%, el de 1976 contabilizó un 68\%, para 1992 un 58,3\% (CRUZ RODRIGUEZ, 2012, p. 34) en tanto que la medición de 2001 había arrojado el dato que $62 \%$ de la población boliviana se definía a sí misma como indígena. Los resultados de los censos en estas cuestiones siempre dependen de las opciones de respuesta que se presenten y las tendencias del contexto socio-político-ideológico del momento histórico en que se realiza el relevamiento 
(ALBÓ, 2009). Un dato no menor, y controvertido, es que el censo mencionado en último término no incluía la categoría "mestizo" por lo que ha hecho referencia a un "mesticidio estadístico".

El resultado de la información del Censo Nacional de 2012 recogida por el Instituto Nacional de Estadística (INE) de Bolivia determinó que de 6.916.732 personas de 15 o más años, 4.032.014 (58\%) negaron pertenecer a algunas de las naciones o pueblos indígenas originarios y 2.806 .592 (41\%) afirmaron una pertenencia. Es decir, según los censos se habría dado entre los años 2001 y 2012 una notable disminución de la proporción y número de indígenas en Bolivia. Las razones para esta variación no pueden obedecer solamente a "... discrepancias en la manera como se recabaron los datos en los últimos dos censos, más que a una tendencia real de crecimiento negativo" (BANCO MUNDIAL, 2015).

Como boliviana o boliviano ¿pertenece a alguna nación o pueblo indígena originario campesino o afroboliviano?, era la pregunta 29 de la encuesta, en la que el empadronador no podía leer las opciones de respuesta. Los quechuas, con 1.281 .116 (el 46\% dado por 654.809 mujeres y 626.307 hombres), y los aymaras, con 1.191 .352 (42\% conformado por 598.535 mujeres y 592.817 hombres) comparativamente lideran la lista de los grupos de población indígena. Les siguen los chiquitanos con 87.885 (3\%), los guaraníes con 58.990 (2\%), los mojeños con 31.078 (1\%). Respecto a los afrobolivianos, se indica que son 16.329 $(0,58 \%)$.

El debate central está dado por la concepción histórica y presente de los llamados mestizos:

En agosto de 2012, el Gobierno descartó incluir la categoría "mestizo" en la boleta censal, porque fue considerada racial y discriminatoria y no se contemplaba en la Constitución Política del Estado. El viceministro de Descolonización, Félix Cárdenas, declaró a ANF que las personas que se consideran mestizas no tienen territorio ni cultura ni religión ni idioma, y que el término sólo representa la construcción "colonial" definida en tres estamentos, el blanco, el criollo y el mestizo. (LA RAZÓN, 2013)²

Volviendo al censo del 2001 y la cuestión de los mestizos, se encuentran opiniones que señalan una falta de realismo de los datos obtenidos ya que todas las restantes encuestas ofrecen cifras que rondan un $67 \%$ de mestizos y sólo de $16 \%$ de indígenas por lo

\footnotetext{
${ }^{2}$ La Razón, 2013. 2,8 millones dicen pertenecer a nación o pueblo indígena. Leído el 15/02/2016 en: http://www.la-razon.com/index.php?_url=/suplementos/especiales/millones-pertenecer-nacion-puebloindigena_0_1880212017.html
} 
que la etnización de la política a partir de esta única información censal y del concepto que los pueblos originarios habrían mantenido incólumes sus costumbres, sus culturas, y que ellos, como variedad de naciones que deberían ser la base de un Estado plurinacional, ha llevado, en la práctica, a un tránsito a la monoculturalidad, pues tras de las loas a todos los pueblos originarios, en realidad lo que se sobrevalora y se pone como el centro del discurso estatal, es todo aquello que proviene de la cultura aymara (TORANZO ROCA, 2009, p. 54-55). Sin ánimo de pretender tomar partido en torno a esta imputación, cabe recordar aquí que Tiwanaku, la whipala, Tupac Atari, Bartolina Sisa y hasta el propio Evo Morales se asocian y son referencias simbólicas provenientes del mundo aymara. Es interesante la siguiente reflexión sobre los cambios en la concepción de lo mestizo en los últimos años en Bolivia:

Hasta hace unas décadas parecía que la palabra mestizo había resuelto un problema histórico, o estaba en camino de resolverlo. íbamos a encontrarnos como sociedad en esta idea, una idea muy amplia, un gran paraguas definiendo el mestizaje como el resultado creativo de la mezcla. Pero ahora la palabra mestizaje se pone en cuestión, porque en teoría representa el intento de imponer una visión de una mezcla carente de esencia, una mezcla en la que una lengua, una religión y una visión uniforme de todo, está disfrazando la realidad compleja y múltiple de lo que en Bolivia definimos como la suma de las naciones indígenas y el Estado Plurinacional en el que formal y oficialmente se ha convertido la nación en una nación de naciones, sustituyendo el concepto "República" por el de "Estado Plurinacional". La palabra mestizo en consecuencia es objetada por muchos estudiosos, antropólogos, historiadores e historiadores del arte, que dicen que no es una palabra que refleje realmente la complejidad del mundo andino. (MESA GISBERT, 2011, p. 58)

En relación a Perú, Peralta Ruiz ofrece la interpretación que, de algún modo, encuentra cierta similitud con lo que acontece en otros países de la región cuando señala que

... quienes se encuentran desvinculados directamente del universo rural e indígena, sienten que pueden resolver parte de su identidad participando de esa continua introspección criolla y mestiza llama indigenismo. Por eso los indigenistas, más que dar cuenta de la identidad de los indígenas, reflejan el eclecticismo de un pensamiento criollo que se niega a reconocerse y proyectarse sobre sí mismo. Al ponerse como meta el conocimiento de la tradición andina, para rescatarla como símbolo de peruanidad, los indigenistas lo hacen renegando de su propia heterogénea herencia cultural. (PERALTA RUIZ, 1995, p. 292)

Señala Martín-Sánchez (2011) que en las discusiones sobre el indigenismo, dos asuntos mantienen plena vigencia en el debate: la proporción de indígenas y el peso del mundo rural con el que se los identificaba ya en tiempos del gobierno de Velasco Alvarado y 
agrega que "... identificar, contar y localizar a los indígenas eran operaciones constitutivas del mismo problema por resolver. Según cómo se llevaran a cabo esas operaciones y según cuál fueran sus resultados, cambiaba el panorama" (MARTÍN-SÁNCHEZ, op. cit., p. 211-212). El mismo autor refiere que en 1972 Marroquín, basado en el censo de 1961, señalaba que la población indígena estaría en torno al $40 \%$ en tanto que para Favre, basado en el censo de 1972, sería del 31\% indicando una clara tendencia decreciente en el porcentaje de población indígena respecto del total nacional.

En Chile mapuches, aymaras y rapa nui entre los censos 1992 y 2002, la población "disminuyó" en los tres casos en esos diez años. En términos absolutos, en 2002 fueron empadronados casi 420 mil mapuches menos que en 1992, de un total de casi un millón. En términos relativos, el pueblo rapa nui registró entre el $15 \%$ y $20 \%$ menos de lo que fue declarado inicialmente. También llaman la atención los datos sobre distribución según sexo y edad.

En Ecuador el censo realizado en el mismo año que en Bolivia (2001) arrojó como resultado que se autoidentificaron como mestizos un $74 \%$ de la población, blancos un $11 \%$, afrodescendiente (negro y mulato) un 6\% e indígenas sólo el 7\% (WALSH, 2010, p. 112). Una compulsa anterior, del año 1950, arrojó que el 14\% de los habitantes eran quichua hablantes (CRUZ RODRIGUEZ, op.cit.). Las dificultades propias del instrumento de la autoidentificación se hacen evidentes con la desazón y controversias que generan las distintas lecturas de las cifras resultantes de cada censo. Seguramente muchas veces el error está en pretender separar binariamente mestizos e indígenas cuando ni siquiera los propios interpelados tienen una definición clara al respecto y, a veces, no le otorgan al dato una relevancia similar a la que le asignan aquellos más interesados o comprometidos ideológicamente con el desarrollo de las políticas públicas.

En Brasil la autoidentificación, junto a la toma de conciencia y el empeño sociopolítico -a raíz del Plan de Acción- acerca del reconocimiento de pueblos indígenas y afrodescendientes, ha sido tal vez el motivo por el cual el registro de los pueblos indígenas evidenció un aumento, reflejado en una tasa media de crecimiento de $11 \%$ al año (RODRÍGUEZ WONG y SÁNCHEZ, 2014). Nótese que este crecimiento se habría dado a lo largo de la década de los noventa, coincidiendo con grandes movimientos de lucha por la 
visibilidad de grupos minoritarios especialmente impulsado en tiempos del auge neoliberal de fines del siglo XX.

En Argentina la sanción de una ley nacional que estableció la incorporación de la temática indígena en el Censo Nacional de Población, Hogares y Viviendas 2001 se enmarca en este proceso regional latinoamericano (GOLDBERG, op. cit.). Hasta entonces la diversidad étnica de la población no era considerada relevante en de cara al ideal de nación que se había instalado mayoritariamente en las representaciones sociales del país en una construcción que incluyó matanzas y persecuciones padecidas por los indígenas y, también, otros grupos. Progresivamente, con el transcurrir del siglo veinte, se consideró a los grupos indígenas como minorías que en su casi totalidad se encontraban integradas a la cultura "nacional".

Según cifras oficiales, en la Argentina viven más de treinta pueblos indígenas, que hablan trece lenguas y representan el $2,4 \%$ de la población total del país, de la cual el $18 \%$ habita en ámbitos rurales organizados en más de 1600 comunidades, en una extensión de tierras cuyo número aún se desconoce y que se estima en más de 14.000 .000 de hectáreas. García Moritán y Cruz (2012, p. 158) reseñan que durante los años 2004/2005 se desarrolló en todo el país la Encuesta Complementaria de Pueblos Indígenas (ECPI). Su resultado consignó la existencia de 281.959 hogares indígenas que permitieron establecer, como mínimo, una población de más de 600.329 aborígenes, pertenecientes a 31 etnias. Según el Censo Nacional de Población, Hogares y Viviendas del año 2010, 955.032 personas se autorreconocen como indígenas y habitan en 368.893 hogares; constituyen el $3 \%$ de los hogares. Ese mismo censo registraba, entre los principales, los siguientes pueblos: Atacama, Ava guaraní o Guaraní, Aymara, Chané, Charrúa, Chorote, Chulupí, Comechingón, Diaguita/diaguita calchaquí, Huarpe, logys, Kolla, Lule, Mapuche, Mbyá, Mocoví, Nivaclé, Ocloya, Omaguaca, Selk'nam u Ona, Pampa, Pilagá, Quechua, Querandí, Rankulche, Sanavirón, Tapiete, Tehuelche, Toba, Tonocoté, Tupí guaraní, Vilela y Wichí (Ministerio de Justicia y Derechos Humanos de la Nación, 2015). En algunas provincias, los pueblos indígenas representan un porcentaje más alto con relación a su población total: Chubut $(8,7 \%)$, Neuquén (8\%), Jujuy $(7,9 \%)$, Río Negro $(7,2 \%)$, Salta $(6,6 \%)$ y Formosa $(6,1 \%)$. Otra estimación oficial indica que, sumada la población aborigen rural no contabilizada, habría un total de 1.012.000 aborígenes en el territorio nacional. Por su parte, la Asociación Indígena 
de la República Argentina (AIRA) estima que existirían alrededor de 1.500 .000 indígenas, mientras que para el Equipo Nacional de Pastoral Aborigen (ENDEPA) su número ascendería, quizás, a 2 millones. No cabe duda que la diversidad de cifras obtenidas en tan corto tiempo como resultado de una misma medición pone en duda el valor de las encuestas o, al menos, la necesidad de estudiar en detalle la metodología utilizada en su elaboración y el contexto político en que fueron concebidas e implementadas.

En el país el nuevo discurso puede ser asumido por buena parte de los sectores políticos y sociales pues no plantea un compromiso efectivo de cara a la realidad social, económica y ambiental pero sí algunos reacomodamientos en las políticas destinadas a determinados pobladores de las zonas económicamente periféricas y de baja densidad de población para quienes, en la medida que se organicen jurídicamente en comunidades indígenas basados en el concepto de autoadscripción dando lugar a procesos de multiplicación y diseminación étnica. Para los grupos así organizados se plantean desde el Estado beneficios específicos tales la "devolución" de tierras (promesa que se cumple a cuentagotas de la mano de una compleja estructura política, legal y administrativa, estando generalmente circunscripta solo aquellas tierras que no se encuentran en manos de particulares), sistemas de becas, subsidios, "restitución" de restos óseos humanos de época prehispánica (hecho que también, rara vez se cumple en la práctica), etc. Aranda (2010, p. 17) afirma que el $60 \%$ de los argentinos tiene antecedentes indígenas y componentes genéticos amerindios de los pueblos nativos. Este dato que permite suponer que se encuentran descendientes de indígenas en todas las grandes ciudades del país, incluyendo la de Buenos Aires. Sin embargo allí los derechos y las demandas de, por ejemplo, la restitución de tierras para esos lugares no están siquiera planteadas como parte de su escenario político cotidiano como lo están para las porciones del territorio nacional económicamente más relegadas.

\section{Consideraciones finales}

Se suele justificar la importancia de importancia de los censos de pueblos indígenas en razón de que han adquirido una inserción débil y excluyente debido, al menos en parte, a su origen étnico (Schkolnik y Del Popolo, 2005). Esto permitiría detectar los principales problemas y establecer metas para su superación mediante políticas de "focalización del 
gasto" público. En general los resultados de los censos son herramientas para el planteo de políticas públicas por lo que las consideraciones metodológicas deben ser desarrolladas con rigurosidad y continuidad para que los datos que se obtengan resulten apropiados e inobjetables. En este sentido resulta fundamental que tanto los responsables del censo como la población censada tengan certeza sobre el significado de los términos utilizados e imparcialidad al momento de la consulta para alcanzar datos objetivos que puedan ser valorados y utilizados adecuadamente con ulterioridad. Sería conveniente que los censos no resulten un mero reflejo de las ideologías o intereses de la época y el humor ciudadano en relación a la coyuntura política propia del momento de su realización y que los resultados alcanzados no puedan ser desvirtuados por las interpretaciones ulteriores. Un censo no puede devenir en una especie de plebiscito ya que con ello pierde su esencia.

En la práctica, sin embargo, las mediciones de poblaciones indígenas muestran una volatilidad de los resultados censales y divergencias en torno a las categorías elegidas. Estos hechos tienen connotaciones y consecuencias políticas destacadas, entre las cuales se encuentra el debate en torno a la consideración de la validez e importancia de la autoadscripción individual como factor determinante para indicar la pertenencia a un determinado grupo étnico. Resulta evidente que los censos nacionales revelan, a través de sus clasificaciones, las ideologías e intereses predominantes sobre la composición étnica de las naciones al momento de su concepción (Goldberg, 2007). El criterio lingüístico suele ser el más frecuentemente usado para las estimaciones censales de la población indígena dada su valoración como elemento cultural nodal en el proceso de sociabilización de la comunidad. El hecho de que el $80 \%$ de los paraguayos hablan el guaraní y sólo el $2,6 \%$ de la población total es considerado indígena (Bonfil Batalla, op. cit., p. 106) en tanto que, por dar otro caso, en el noroeste argentino los distintos grupos étnicos identificados en la actualidad en su casi totalidad solo hablan castellano son ejemplos que se contraponen con la elección del idioma como referencia indicadora de etnicidad.

Otro factor que se considera con frecuencia, pero cuyo análisis pormenorizado suele presentar evidentes debilidades es la atribución de antepasados comunes que, en opinión de Lloréns, “... no equivale a una percepción biológica sino más bien cultural, remitiéndose por lo general a un pasado no necesariamente mítico o muy antiguo, pero sí mínimamente remoto como para hacer difícil por lo general establecer para cada miembro 
del grupo una línea directa con los primeros antepasados que se atribuyen" (Lloréns, 2002, p. 663).

La importancia dada a los censos al presente no es menor. En el caso de Bolivia, el censo del 2012, y su comparación con los datos obtenidos en el 2001, dio lugar a que la oposición política al gobierno de Evo Morales señalara que los indígenas, en su conjunto, dejaron de ser mayoría a nivel nacional y que el espacio le correspondería a los mestizos (es decir, a los llamados "ningunos"). Para algunos los resultados de estas sucesivas mediciones abren el debate en torno al principal sustento argumental que dio lugar a la existencia del Estado Plurinacional, y a la carta magna que le diera origen, vigente desde el 7 de febrero de $2009^{3}$ aunque bien puede considerarse legítimo que un estado de plurinacionalidad no necesariamente debe estar cimentado en mayorías porcentuales.

Los resultados de los censos más recientes a los que aquí se hace referencia parecen reflejar grandes dificultades de los organismos gubernamentales para conocer y caracterizar la diversidad y complejidad que caracteriza a la sociedad en su conjunto y, más aún, para desligar las consultas censales de la coyuntura política transnacional. Se requiere un compromiso social y de conocimiento más profundo al momento de la determinación de las particularidades que hacen a la población y que, por lo tanto, se desea conocer y medir. Y comprender que, con frecuencia, hay situaciones y circunstancias sociales, culturales e históricas que no son mensurables por lo que se necesitan otras herramientas de aproximación para intentar comprender realidades sociales para lo que se requiere de elaboraciones más complejas y focalizadas.

\section{BibLIOGRAFÍA}

ALBÓ, X. Muchas naciones en una. In: ROJAS ORTUSTE, Gonzalo (Coord.) ¿Nación o naciones boliviana(s)? Institucionalidad para nosotros mismos. La Paz/Bolivia: CIDES-UMSA, 2009, p. 63-98. ARANDA, D. Argentina originaria: genocidios, saqueos y resistencias. La Vaca Editora, 2010.

BONFIL BATALLA, G. El concepto de indio en América: una categoría de la situación colonial. Anales de Antropología, vol. 9, p. 105-124, UNAM, 1972.

BANCO MUNDIAL, 2015. Latinoamérica Indígena en el Siglo XXI. Washington, D.C.: Banco Mundial. Licencia: Creative Commons de Reconocimiento CC BY 3.0 IGO. 
BASTOS, S. Los indios, la nación y el nacionalismo. Espiral, vol. II, núm. 6, p. 161-206 Universidad de Guadalajara Guadalajara, México, 1996.

BRAVO-MORENO, A. Educando y aprendiendo desde procesos de racialización. Gazeta de Antropología, n. 31 (1), 2015. Leído el 12/01/2016 en: http://hdl.handle.net/10481/34251.

CARRASCO, T.; ALCÁZAR, T. Los pueblos indígenas y los censos en México y América Latina: La cultura en la definición de su identidad. In: VALDÉS, Luz María (coord.). Derecho de los mexicanos. Introducción al derecho demográfico. Acervo Biblioteca Jurídica Virtual del Instituto de Investigaciones Jurídicas, UNAM. Leído el 14 de junio de 2017.

CRUZ RODRÍGUEZ, E. El "problema indígena" y la construcción de la nación en Bolivia y Ecuador durante el siglo XIX: la perspectiva de las luchas por la hegemonía. Diálogos Latinoamericanos, n. 19, p. 33-68, Aarhus Universitet, Dinamarca, 2012.

GARCÍA MORITÁN, M.; Cruz, M. Comunidades Originarias y Grupos Étnicos de la provincia de Jujuy. Población \& Sociedad, vol. 19 (2), 2012, p. 155-173. http://www.poblacionysociedad.org.ar/archivos/19/P\&S-V19-N2-GarciaMoritan-Cruz.pdf

GOLDBERG, C. Reflexiones en torno a la medición de la etnicidad en censos y encuestas. IX Jornadas Argentinas de Estudios de Población. Asociación de Estudios de Población de la Argentina, Huerta Grande, Córdoba.

GONZÁLEZ PONCIANO, J. R. Multiculturalismo, mayanización y política pública. In: BASTOS, S. (compilador). Multiculturalismo y futuro en Guatemala. Flacso/Oxfam, 2008, p. 97-122.

GROSSO, J. L. Indios muertos, negros invisibles. Hegemonía, identidad y añoranza. 1ạ. Ed. Córdoba: Grupo Encuentro Editor, 2008.

GUANUMEN, M. Are we the people? Indígenas en Estados Unidos, en los márgenes del sueño americano. Ciudad Paz-ando, 6 (2), 2013, p. 6-33.

JASPERS-FAIJER, D. Presentación. In: Documento de proyecto Comisión Económica para América Latina y el Caribe (CEPAL) Pueblos indígenas y afrodescendientes de América Latina y el Caribe: información sociodemográfica para políticas y programas. Santiago de Chile, 2006.

KULEMEYER, J. A. Pobreza y exclusión de las periferias etnizadas e idealizadas. In: GILI, María Laura; PÉREZ ZAVALA, Graciana (comps.). Estudios Latinoamericanos. Diálogos interdisciplinarios sobre sociedad, historia, cultura, frontera y territorio. Buenos Aires: Secretaría de Políticas Universitarias, Universidad Nacional de Villa María, Editorial ASPHA, 2015.

LÓPEZ, L. De transnacionalización y censos. los "afrodescendientes" en Argentina. AlBR. Revista de Antropología Iberoamericana, vol. 1, n. 2, marzo-julio, 2006, p. 265-286. Asociación de Antropólogos Iberoamericanos en Red Madrid, Organismo Internacional.

LLORÉNS, J. Etnicidad y censos: los conceptos básicos y sus aplicaciones. Boletín del Instituto Francés de Estudios Andinos, año/vol. 31, n. 3: 655-680, Instituto Francés de Estudios Andinos, Paris, 2002.

MARQUIEGUI, D. Del crisol de razas al pluralismo cultural: el debate historiográfico como herramienta orientadora de las estrategias para la enseñanza de la historia. Clío y Asociados. La Historia Enseñada, n. 4, 1999, p. 37-54. 
MARTÍN-SÁNCHEZ, J. Indigenismo bifronte en el gobierno peruano de Velasco Alvarado: continuidad y alternativa, sierra y selva. In: GIRAUDO; MARTÍN-SÁNCHEZ (compiladores). La ambivalente historia del indigenismo: campo interamericano y trayectorias nacionales, 1940-1970. IEP Instituto de Estudios Peruanos, 2011, p. 191-250.

MESA GISBERT, C. Historia e identidad. Construcción del mestizaje e imaginarios culturales-religiosos. In: Entre cielos e infiernos. Memoria del $V$ Encuentro Internacional sobre Barroco. Pamplona: Fundación Visión Cultural/Servicio de Publicaciones de la Universidad de Navarra, 2011, 57-61. Edición digital a partir de La Paz, Fundación Visión Cultural, 2010.

MINISTERIO DE JUSTICIA Y DERECHOS HUMANOS DE LA NACIÓN. Derechos de los pueblos indígenas en la Argentina, una compilación. Compilado por Demicheli Calcagno; S.; Canet, V.; Virosta, L. Ciudad Autónoma de Buenos Aires: Ministerio de Justicia y Derechos Humanos de la Nación. Secretaría de Derechos Humanos, 2015. 576 páginas.

PERALTA RUIZ, V. Indigenismo, nacionalismo y modernidad en el Peru. In Visión de los otros y visión de sí mismo Descubrimiento o invención entre el nuevo mundo y el viejo? Madrid: Consejo Sup. Investigaciones Científicas, 1995, p. 273- 292.

QUENALLATA, R. Censo: menos indígenas es un mensaje político. Opinión. La Paz/Bolivia, 11/08/2013. Leído el 15/02/13 en: http://www.opinion.com.bo/opinion/articulos/2013/0811/noticias. php?id=102888

RIVERA CUSICANQUI, S. La antropología y la arqueología en Bolivia: límites y perspectivas. América Indígena 40 (2), 1980, p. 217-224.

RODRÍGUEZ WONG, L.; SÁNCHEZ, J. Esfuerzos para el avance en la investigación demográfica sobre la población afro-descendiente e indígena en América Latina: rezagados entre los rezagados - Una introducción. In: Situación de la población afro descendiente e indígena en América Latina - puntos de reflexión para el debate sobre Cairo + 20. Belo Horizonte: ALAP, 2014. (Serie e-Investigaciones; 4).

ROUVIÈRE, L. Gobernar territorialidades transfronterizas. Seguridad y "desarrollo con identidad" aymara en la triple frontera del norte de Chile (Chile-Perú-Bolivia). Trace, n. 65, 2014, p. 37-50.

SCHKOLINK, S.; DEL POPOLO, F. Los censos y los pueblos indígenas en América Latina: Una metodología Regional. In: Seminario Internacional Pueblos indígenas y afrodescendientes de América Latina y el Caribe: relevancia y pertinencia de la información sociodemográfica para políticas y programas CEPAL, Santiago de Chile, , 2005.

TORANZO ROCA, C. Repensando el mestizaje en Bolivia. In: ROJAS ORTUSTE, Gonzalo (Coord.). ¿Nación o naciones boliviana(s)? Institucionalidad para nosotros mismos. La Paz, Bolivia, 2009, 45-62.

YUDI, R. Kollas de nuevo. Etnicidades, trabajo y clasificaciones sociales en los Andes de la Argentina. . Jujuy: Purmamarka Ediciones, 2015.

WALSH, C. Raza, mestizaje y poder: horizontes coloniales pasados y presentes. Crítica y Emancipación. Revista Latinoamericana de Ciencias Sociales, Año II, n. 3; p. 95-124. Buenos Aires: CLACSO, 2010. 